\title{
Differences in Venous Thromboembolism Prevention and Outcome between Hospitalized Patients with Solid and Hematologic Malignancies
}

\author{
Rocío Figueroa ${ }^{1}$ Ana Alfonso ${ }^{1}$ María Marcos ${ }^{1}$ \\ Ignacio Gil-Bazo ${ }^{2}$ José Rifón ${ }^{1}$ José Hermida ${ }^{4,5}$ \\ ${ }^{1}$ Hematology Service, Clínica Universidad de Navarra, Pamplona, \\ Navarra, Spain \\ 2 Department of Oncology, Clínica Universidad de Navarra, Pamplona, \\ Navarra, Spain \\ ${ }^{3}$ Informatics Service, Clínica Universidad de Navarra, Pamplona, \\ Navarra, Spain \\ ${ }^{4}$ Center for Applied Medical Research, University of Navarra, \\ Pamplona, Navarra, Spain \\ ${ }^{5}$ CIBER-CV, Pamplona, Navarra, Spain
}

TH Open 2019;3:e153-e156.

Venous thromboembolism (VTE) is a common complication in cancer patients, leading to significant morbidity, mortality, and resources consumption. Around 20\% of VTE events are related with an underlying malignancy. ${ }^{1}$ The incidence of cancer-associated thrombosis is increasing in recent years due to different reasons such as longer survival and improved sensitivity of imaging techniques. Hospitalization is a recognized additional risk factor. ${ }^{2}$ Current evidence-based clinical practice guidelines (CPGs) uniformly recommend pharmacological prophylaxis with low-molecular-weight heparin (LMWH) in hospitalized cancer patients, unless contraindicated. ${ }^{3-5}$ However, the quality of the evidence that supports LMWH prophylaxis in cancer inpatients is not strong as recommendations are based on the results of clinical trials involving medical inpatients with different conditions (not only cancer). ${ }^{6}$ CPG statement applies to both, solid and hematologic malignancies, given that a similar VTE-associated risk has been reported. In fact, in the validated Khorana's risk assessment model, lymphoma is regarded as a high-risk tumor-site category. ${ }^{7}$

In this article, we have evaluated the rate of thromboprophylaxis use and outcome in daily clinical practice in consecutive hospitalized cancer patients, focusing in the differences between patients with solid or hematologic cancer.

In this prospective cohort study, consecutive adult ( $\geq$ 18 years old) cancer patients, not receiving anticoagulant therapy, admitted in the Department of Oncology and

received

March 7, 2019

accepted after revision

April 24, 2019
José María López-Picazo ${ }^{2}$ Alberto García-Mouriz ${ }^{3}$

José Antonio Páramo ${ }^{1,5}$ Ramón Lecumberri ${ }^{1,5}$
Address for correspondence Ramón Lecumberri, MD, PhD, Servicio de Hematología, Clínica Universidad de Navarra, Avenida Pío XII, 36, 31008 Pamplona, Navarra, Spain (e-mail: rlecumber@unav.es).
Hematology at the University Clinic of Navarra were recruited. Patients undergoing bone marrow transplantation were excluded. The study was approved by the institutional Ethics Committee (P88/2013) and all patients signed an informed consent. The risk of VTE of all inpatients was automatically calculated by using an application of our electronic clinical history software following the PRETEMED score. ${ }^{8-10}$ In this point scale, major risk factors such as active cancer, previous VTE, acute myocardial infarction, ischemic stroke with limb paralysis, decompensated chronic obstructive pulmonary disease, and thrombophilia were assigned a score of 3; congestive heart failure, chronic renal insufficiency/nephrotic syndrome, severe acute infection, lower limb cast, and prolonged bed rest were assigned a score of 2; and pregnancy/postpartum period, recent prolonged flight, lower limb paresis, estrogen therapy, thalidomide/ lenalidomide administration, use of central vein catheter, obesity, age greater than 60 years, and smoking were assigned a score of 1 . High risk of VTE was defined as a cumulative score of at least 4 points. According to our institutional thromboprophylaxis protocol, medical inpatients with high risk of VTE should receive 3,500 IU of bemiparin daily, unless contraindicated. The primary outcome of the study was the rate of thromboprophylaxis use. Secondary endpoints were the incidence of objectively confirmed VTE (events diagnosed in the first 24 hours after admission were excluded), major bleeding (according to the definition of the International Society on Thrombosis and
License terms

Stuttgart · New York
DOI https://doi.org/

10.1055/s-0039-1692203. ISSN 2512-9465. 
Haemostasis), ${ }^{11}$ and mortality during follow-up. Follow-up period starts from admission to 30 days after discharge. Categorical variables were expressed as frequencies and percentages, and quantitative variables as either mean ( \pm standard deviation) or median depending on distribution. The chi square/Fisher's exact tests were used to compare proportions. Type I error was established in 0.05. Statistical analyses were performed using IBM SPSS Statistics (version 22.0, Chicago, Illinois, United States) software.

From April 2014 to February 2017, a total of 1,072 consecutive adult cancer patients were included, 217 (20.2\%) of them with a hematologic malignancy. The main characteristics of recruited patients, according to tumor type, are shown in -Table 1. There were no differences between groups regarding age, gender, length of stay, or active treatment. Of note, $15.2 \%$ of patients with hematologic cancer presented thrombocytopenia less than $50 \times 10^{9} / \mathrm{L}$, compared with $3.5 \%$ of those with solid neoplasm. According to the PRETEMED score, 93\% of patients were considered as high risk. The rate of $\mathrm{LMWH}$ thromboprophylaxis during admission was 43.3 and $73.8 \%$ in patients with hematologic and solid cancer, respectively (risk difference: $0.30 ; 95 \%$ confidence interval [95\% CI]: $0.23-0.38 ; p<0.001)$. The proportion of patients with low risk of VTE receiving
LMWH was similar inside each subgroup: 5 of 14 (35.7\%) patients with hematologic malignancy and 48 of 69 (69.5\%) patients with solid tumors. Exclusion of low-risk patients did not vary the overall results. A survey, limited to high-risk patients, revealed that in $40 \%$ of hematologic patients not receiving $\mathrm{LMWH}$ prophylaxis during admission, the reason to withhold it was the responsible physician's opinion that the patient's risk was not high. This number was markedly lower, $10 \%$, for inpatients with solid malignancies.

A total of 30 VTE events were observed during follow-up, 5 (2.3\%) in hematologic patients and $25(2.9 \%)$ in patients with solid cancer (relative risk [RR]: 0.79, 95\% CI: 0.30-2.03; $p=0.79$; - Fig. 1). All the events developed in patients with high-risk score. Interestingly, in hematologic patients, four of the five episodes (80\%) were catheter-related deep vein thrombosis (CR-DVT), and three of the five happened in patients not receiving prophylaxis with $\mathrm{LMWH}$, one of them in a patient with a platelet count less than $50 \times 10^{9} / \mathrm{L}$. In patients with solid cancer, 6 of 25 events (24\%) were CR-DVT and 22 of 25 (88\%) occurred despite appropriate thromboprophylaxis during admission. The rates of major bleeding during hospitalization and 30 days after discharge were low in both groups (1.8 vs. 3.9\%; RR: 0.48, 95\% CI: 0.17-1.33; $p=0.21$ ). Gastrointestinal hemorrhage was the most frequent bleeding site in both

Table 1 Clinical characteristics of recruited patients

\begin{tabular}{|c|c|c|c|c|}
\hline & Total & Solid & Hematologic & $p$ \\
\hline$N$ & 1,072 & 855 (79.8\%) & $217(20.2 \%)$ & \\
\hline Age (mean \pm SD) & $62.1 \pm 13.3$ & $61.7 \pm 13.3$ & $63.4 \pm 13.4$ & ns \\
\hline Sex (male/female) & $626 / 446$ & $493 / 362$ & $133 / 84$ & ns \\
\hline Length of stay (days) (median, range) & $5(1-140)$ & $5(1-97)$ & $5(1-140)$ & ns \\
\hline \multicolumn{4}{|l|}{ Cancer site $(n, \%)$} & \multirow[t]{14}{*}{-} \\
\hline Colorectal & $177(16.5 \%)$ & $177(20.7 \%)$ & & \\
\hline Lung & $161(15.0 \%)$ & $161(18.8 \%)$ & & \\
\hline Gastrointestinal & $96(9.0 \%)$ & $96(11.2 \%)$ & & \\
\hline Gynecologic & $80(7.5 \%)$ & $80(9.4 \%)$ & & \\
\hline Pancreas & $77(7.2 \%)$ & $77(9.0 \%)$ & & \\
\hline Renal/Urinary & $44(4.1 \%)$ & $44(5.1 \%)$ & & \\
\hline Breast & $42(3.9 \%)$ & $42(4.9 \%)$ & & \\
\hline Prostate & $37(3.5 \%)$ & $37(4.3 \%)$ & & \\
\hline Other solid & $141(13.2 \%)$ & $141(16.5 \%)$ & & \\
\hline Lymphoma & $136(12.7 \%)$ & & $136(62.7 \%)$ & \\
\hline Myeloma & $56(5.2 \%)$ & & $56(25.8 \%)$ & \\
\hline Leukemia & $21(2.0)$ & & $21(9.7 \%)$ & \\
\hline Other hematologic diseases & $4(0.4 \%)$ & & $4(1.8 \%)$ & \\
\hline Metastatic disease $(n, \%)$ & - & $578(67.6 \%)$ & & - \\
\hline Chemotherapy $(n, \%)$ & $880(82.1 \%)$ & $694(81.1 \%)$ & $186(85.7 \%)$ & $\mathrm{ns}$ \\
\hline Platelets $<50 \times 10^{9} / \mathrm{L}(n, \%)$ & $63(5.9 \%)$ & $30(3.5 \%)$ & $33(15.2 \%)$ & $<0.001$ \\
\hline PRETEMED score (median, range) & $5(3-13)$ & $5(3-13)$ & $5(3-13)$ & ns \\
\hline PRETEMED $\geq 4$ points $(n, \%)$ & $989(92.3 \%)$ & 786 (91.9\%) & 203 (93.5\%) & ns \\
\hline
\end{tabular}

Abbreviations: ns, nonsignificant; SD, standard deviation. 


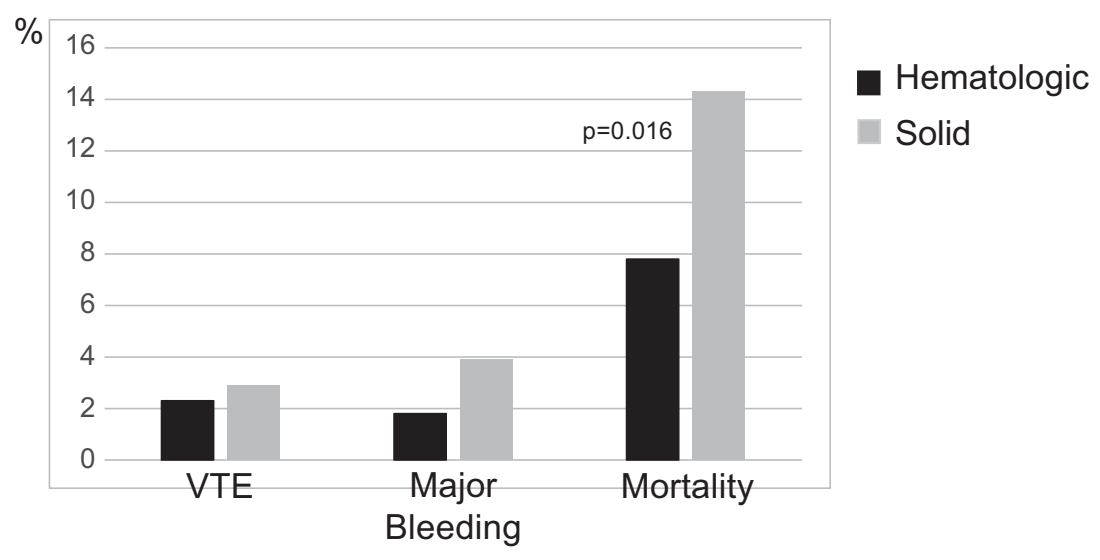

Fig. 1 VTE events, major bleeding, and mortality during follow-up (hospitalization and 30 days after discharge). VTE, venous thromboembolism.

groups of patients. Thromboprophylaxis was not associated with an increased incidence of major bleeding. Mortality during follow-up was 7.8 and $14.3 \%$, respectively (RR: 0.55 , 95\% CI: $0.34-0.89 ; p=0.016)$. Cancer progression was the leading cause of death, while bleeding and VTE were responsible for two and one deaths, respectively.

With the limitations of a single-center investigation, our study confirms a lower use of pharmacological thromboprophylaxis in hospitalized patients with hematologic malignancies compared with subjects with solid cancer. ${ }^{12}$ However, only in a small subset of patients, there was a clear contraindication such as severe thrombocytopenia or active/ recent bleeding. It appears that clinicians do perceive these patients as a lower-risk population, probably because many patients maintained some degree of mobility. ${ }^{13}$ Nevertheless, in our study a higher number of hematologic inpatients showed very high scores in the PRETEMED scale. Unfortunately, we lack data about the use of extended prophylaxis after discharge, which could be necessary in very high risk patients but not routinely prescribed in most cases. ${ }^{14}$ Although the incidence of VTE during or shortly after hospitalization is similar in both groups, some particularities exist. The absolute number of VTE events is low, but the higher proportion of CR-DVT in hematologic patients may be relevant because the effectiveness of LMWH for the prevention of that specific thrombosis site is controversial. ${ }^{15}$ Currently, routine thromboprophylaxis for the prevention of CR-DVT in cancer patients is not recommended. ${ }^{16}$ In addition, this different outcome in terms of thrombus location may imply that cancer site must be taken into account when designing future trials on VTE prevention in cancer patients. ${ }^{17}$ Moreover, in our series, a trend toward a lower bleeding risk, not related with the use of thromboprophylaxis, and a significant lower short-term mortality was observed in hematologic patients. Specific studies in this population are warranted.

Funding

This work has been partially funded by a biomedical research grant by Laboratorios Farmacéuticos ROVI and an aid for research projects from the Instituto de Salud Carlos III and the FEDER (PI13/01029).
Conflict of Interest

None declared.

\section{References}

1 Timp JF, Braekkan SK, Versteeg HH, Cannegieter SC. Epidemiology of cancer-associated venous thrombosis. Blood 2013;122(10): 1712-1723

2 Khorana AA, Francis CW, Culakova E, Kuderer NM, Lyman GH. Frequency, risk factors, and trends for venous thromboembolism among hospitalized cancer patients. Cancer 2007;110(10): 2339-2346

3 Farge D, Bounameaux H, Brenner B, et al. International clinical practice guidelines including guidance for direct oral anticoagulants in the treatment and prophylaxis of venous thromboembolism in patients with cancer. Lancet Oncol 2016;17(10):e452-e466

4 Lyman GH, Bohlke K, Khorana AA, et al; American Society of Clinical Oncology. Venous thromboembolism prophylaxis and treatment in patients with cancer: American Society of Clinical Oncology Clinical Practice Guideline update 2014. J Clin Oncol 2015;33(06):654-656

5 Pachón V, Trujillo-Santos J, Domènech P, et al. Cancer-associated thrombosis: beyond clinical practice guidelines-a multidisciplinary (SEMI-SEOM-SETH) expert consensus. TH Open 2018;2 (04):e373-e386

6 Carrier M, Khorana AA, Moretto P, Le Gal G, Karp R, Zwicker JI. Lack of evidence to support thromboprophylaxis in hospitalized medical patients with cancer. Am J Med 2014;127(01):82-6.e1

7 Khorana AA, Kuderer NM, Culakova E, Lyman GH, Francis CW. Development and validation of a predictive model for chemotherapy-associated thrombosis. Blood 2008;111(10):4902-4907

8 Medrano Ortega FJ, Navarro Puerto A, Vidal Serrano S, et al. Guía PRETEMED - 2007 sobre prevención de enfermedad tromboembólica venosa en patología médica. Córdoba: SADEMI; 2007. Available at: https://www.sademi.com/actividades/publicaciones/guia_medica_pretemed_2007.pdf. Accessed May 10, 2019

9 Smilg Nicolás C, Tornel Sánchez G, Trujillo Santos J. Concordance among venous thromboembolism risk assessment models. Med Clin (Barc) 2018;150(02):61-63

10 Lecumberri R, Marqués $M$, Panizo E, et al. High incidence of venous thromboembolism despite electronic alerts for thromboprophylaxis in hospitalised cancer patients. Thromb Haemost 2013;110(01):184-190

11 Schulman S, Kearon C; Subcommittee on Control of Anticoagulation of the Scientific and Standardization Committee of the International Society on Thrombosis and Haemostasis. Definition of major bleeding in clinical investigations of antihemostatic 
medicinal products in non-surgical patients. J Thromb Haemost 2005;3(04):692-694

12 Zwicker JI, Rojan A, Campigotto F, et al. Pattern of frequent but nontargeted pharmacologic thromboprophylaxis for hospitalized patients with cancer at academic medical centers: a prospective, cross-sectional, multicenter study. J Clin Oncol 2014;32(17): 1792-1796

13 Figueroa R, Alfonso A, López-Picazo J, et al. Insights into venous thromboembolism prevention in hospitalized cancer patients: Lessons from a prospective study. PLoS One 2018;13(08):e0200220

14 Heit JA, Crusan DJ, Ashrani AA, Petterson TM, Bailey KR. Effect of a near-universal hospitalization-based prophylaxis regimen on annual number of venous thromboembolism events in the US. Blood 2017;130(02):109-114

15 Kahale LA, Tsolakian IG, Hakoum MB, et al. Anticoagulation for people with cancer and central venous catheters. Cochrane Database Syst Rev 2018;6:CD006468

16 Debourdeau P, Farge D, Beckers M, et al. International clinical practice guidelines for the treatment and prophylaxis of thrombosis associated with central venous catheters in patients with cancer. J Thromb Haemost 2013;11(01):71-80

17 Agnelli G. Direct oral anticoagulants for thromboprophylaxis in ambulatory patients with cancer. N Engl J Med 2019;380(08): 781-783 